\title{
Spider Bite Inducing Superficial Lymphangitis: A Case Report
}

\author{
El Anzi Ouiam*, Meziane Mariam and Hassam Badredine \\ Department of Dermatology-Venereology, Morocco
}

Received: 橎: December 04, 2018; Published: 䙵: December 17, 2018

*Corresponding author: El Anzi Ouiam, Department of Dermatology-Venereology, Morocco

\begin{abstract}
Superficial lymphangitis after insect bite is the result of an allergic reaction to the insect antigen. We present the case of a 22-year-old patient with no notable medical history, presented with a pruritic rash on the chest, two days after an insect bite. Unlike bacterial lymphangitis, the site of insect bite is not painful but pruritic.
\end{abstract}

Keywords: Spider Bite; Lymphangitis; Allergic Reaction

\section{Introduction}

Superficial lymphangitis after insect bite is the result of an allergic reaction to the insect antigen, which is injected into the skin and drained by lymphatic vessels [1].

\section{Clinical Case}

A 22-year-old female with no notable medical history, presented with a pruritic rash on the chest. She mentioned intense pruritus and low pain. Two days before she had been bitten on the shoulder by a spider.

Physical examination showed a red linear lesion starting from erythematous macule of the shoulder and extending toward the anterior wall of the chest. Neither fever nor lymph node enlargement were present. Cardiovascular exams, Pleuropulmonary and neurologic were normal. A diagnosis of superficial lymphangitis after spider bite was made, based on the history and lesion's characteristic. The patient was treated with oral antihistamines and topical corticosteroids for a week with good evolution.

\section{Comments}

Spiders or aramids are predators' arthropod invertebrates of the class of arachnids, ubiquitous and their bites are common even in urban areas. The spider sting is often asymptomatic thus passing unnoticed [2].

Superficial lymphangitis after spider bite is a rare entity mimicking acute bacterial lymphangitis without fever and lymphadenopathy. Different authors assume that superficial lymphangitis after spider sting is the consequence of an allergic immune reaction due to insect toxins [3]. Unlike bacterial lymphangitis, the site of insect bite is not painful but pruritic. It's also characterised by the absence of fever and lymph node enlargement and a rapid spontaneous regression [1-3] (Figure 1).

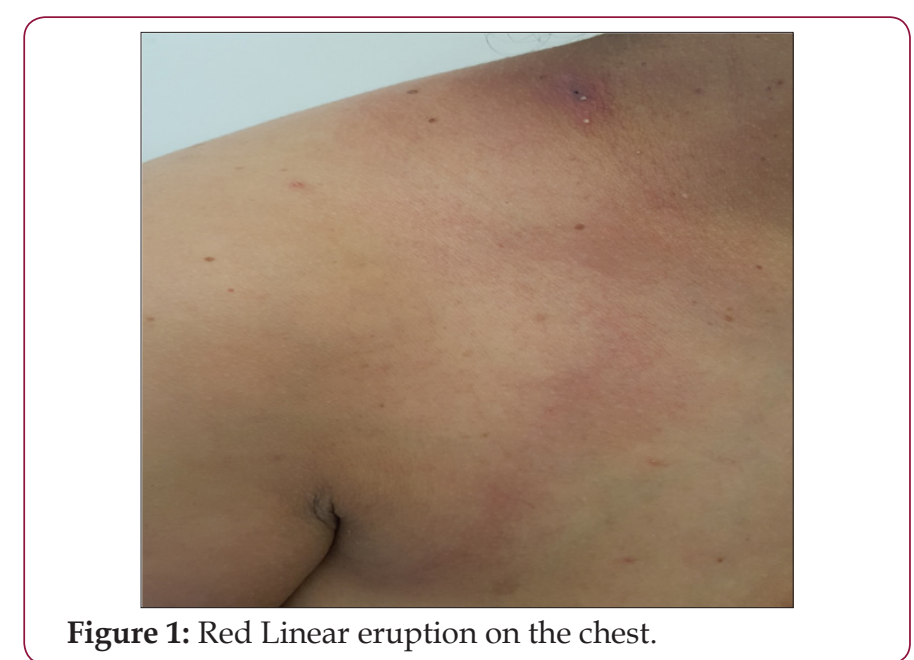

\section{Conclusion}

Lymphangitis secondary to a spider bite constitutes one of the complications not usually encountered, the interrogation is crucial 
to determine the diagnosis, in the absence of general complications, evolution remains benign.

\section{References}

1. Mitsuhito Ota (2016) Allergic lymphangitis. BMJ 355: 15726.

\section{ISSN: 2574-1241}

DOI: $10.26717 / B J S T R .2018 .12 .002232$

El Anzi Ouiam. Biomed J Sci \& Tech Res

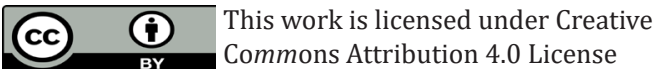

Submission Link: https://biomedres.us/submit-manuscript.php
2. H Benzzi, M Bouaddi, K Jouid, W Raffas, I Ramli, et al. (2013) Piqure d'araignée: encore des surprises. Annalesdedermatologie 140Supply 1: 141.

3. Vincenzo Piccolo, Rosalba Picciocchi, Mario Diplomatico, Orsola Ametrano, Elvira Moscarella (2013) Superficial Lymphangitis after Insect Bite. J Pediatr 163(1): 299.

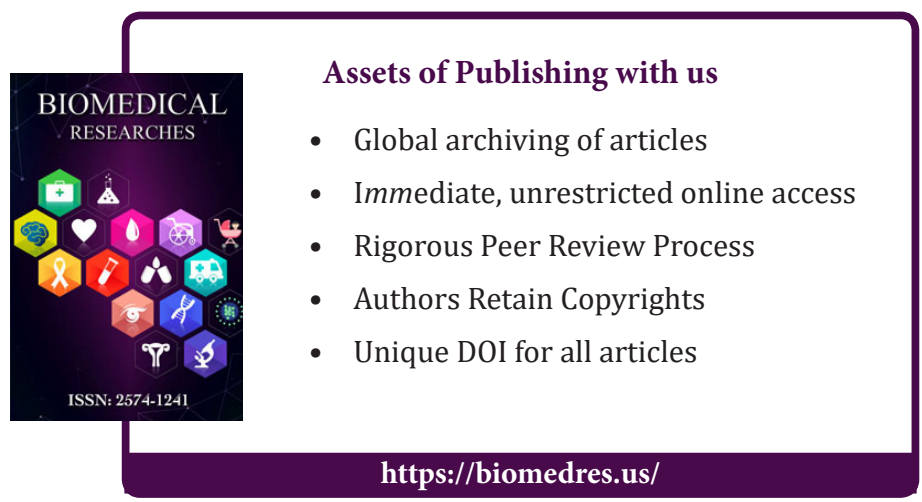

